\title{
Práticas Teatrais e Resistência: entre a desrazão e a governamentalidade
}

\section{Theatrical practices and resistance: between un- reason and governmentality}

Suzana Schmidt Viganó ${ }^{1}$ 


\section{Resumo}

Este artigo levanta questões em torno do teatro como veículo de libertação e resistência política. Busca indicar como o seu potencial enquanto técnica de si e espaço de experiência foi enredado nas malhas da governamentalidade. Indica as questões que tradicionalmente se direcionam ao trabalho artístico como prática pedagógica, procurando refletir sobre as linhas de força que constituem os embates entre poder e liberdade. Concentra-se na experiência do coletivo paulista II Trupe de Choque, em sua residência artística no Hospital Psiquiátrico Pinel, refletindo sobre as formas de resistência e contraconduta gestadas nesse processo.

Palavras-chave: Arte e resistência; teatro e política; ação cultural; grupos de teatro e ação artística

\section{Abstract}

This article raises questions around theater as a vehicle for liberation and resistance. It intends to indicate how its potential as a self-practice and experience has been entangled in the meshes of governmentality. It indicates issues that traditionally address artistic work as a pedagogical practice, trying to reflect on the lines of force that constitute the clashes between power and freedom. It focuses on the experience of the collective II Trupe de Choque, in its artistic residency at the Pinel Psychiatric Hospital, reflecting on the forms of resistance and counter-conduct that were managed in this process.

Keywords: art and resistance; theater and politics; cultural action; theater groups and artistic action.

E-ISSN: 2358.6958

1 Profa. Dra. Licenciatura no Departamento de Artes Cênicas da Universidade de São Paulo ECA/USP) e da Pós-Graduação em Arte-Educação e Gestão Cultural no Senac-SP. suzanaschmidt21@usp.br 
A crítica é igualmente, com efeito - é seu terceiro sentido - a experiência permanente da ultrapassagem. A libertação, não como horizonte de uma liberação definitiva, mas como ultrapassagem, que precisa sempre ser reencenada, das linhas de crise que atravessam um sistema (suas "fronteiras"), tal é, para Foucault, a atitude política que se deve tentar realizar.

(Sennellart, Michel, 1995, p. 12)

A experiência artística de mestres tradicionais do teatro, como Stanislavski e Artaud e, mais contemporaneamente Grotowski e Peter Brook, caminharam no sentido da construção de um treinamento ético-estético que propiciava a transposição para um tempo extra-cotidiano, estabelecendo no espetáculo teatral uma vivência presencial e também íntima que trafegava por universos complexos entre a percepção e a memória do espectador. A questão pedagógica estabelecia-se enquanto experiência numa via de mão dupla, tanto para o espectador quanto para o ator, pois este, ao se treinar em técnicas que passavam pelo aperfeiçoamento do corpo enquanto veículo transmissor, não apenas de signos elaborados semanticamente, mas de um estado diferenciado de presença, colocava-se diretamente em uma zona limiar, não normalizada da experiência, proporcionando a dilatação da sensação espaço-temporal.

No caso de Meyerhold e depois Brecht, apesar do alto grau de sofisticação das técnicas de atuação com relação à corporalidade, uma diferente conexão se estabelecia com o espectador. Por meio de uma matemática da encenação, pretendia-se mantê-lo sempre alerta, tanto para os jogos cênicos de composição que eram ali explicitados, quanto para uma atenção cognitiva sobre os temas propostos em cena, evidenciando, neste modo de se fazer teatro, não a sensorialidade ou a temporalidade como recepção, mas o domínio de uma discursividade linguística, seja sobre os conteúdos, seja sobre a própria linguagem teatral. Meyerhold afirmava que uma das funções do teatro seria estimular a atividade cerebral do espectador.

Ao longo da história, sempre se considerou e se debateu sobre essa questão: qual a função da arte? Teria esta uma função social, como pressuposto, por ser parte expressiva da cultura? Como essa função teria variado, em seus modos de legitimidade, de acordo com os antagonismos entre poder e resistência em diferentes momentos?

E como se passou de arte para arte-educação? Quando a arte saiu da sala de ensaio e ganhou as ruas? Quando ela saiu do âmbito dos artistas e ganhou o âmbito das comunidades? Até meados do século XX as questões da prática artística eram restritas aos artistas, profissionais ou aprendizes e diziam respeito aos desafios estéticos da construção das obras e da relação com o espectador. Não era parte do currículo escolar, não constituíam atividades de alívio da carga de trabalho fabril, não alimentavam os sonhos das comunidades carentes. Foi na apropriação pedagógica, inicialmente na educação infantil, e pelas propostas de mediação cultural do welfare state, em meados dos 50, que a prática artística se democratizou e passou, rapidamente, a ganhar o campo do que posteriormente veio a se solidificar como arte-educação e ação cultural, fortalecendo o campo de conhecimento artístico-pedagógico.

Com o crescimento do neoliberalismo, a arte passou também a se sedimentar nos modos econômicos de produtividade e empreendedorismo, "economizando-se", nos seus modos de produção, por um lado e participando do controle biopolítico das populações, por outro, pelo seu potencial funcionamento como técnica de si. O que mudou, dentro desse quadro, de Stanislavski até os dias de hoje? 
Por meio da arte justifica-se o discurso de recuperar delinquentes e excluídos, de resgatar memórias, fomentar a solidariedade, ou seja, de enriquecer o capital social e também de desenvolver técnicas que pode possibilitem a entrada em um determinado mercado de trabalho. No caso do teatro, por exemplo, o artista surge como um especialista em relações sociais, em criar acordos de grupo e desenvolver senso de comunidade. A própria noção de "multiplicador", formando o arte-educador nas comunidades locais, outorgam à arte a legitimação para a continuidade da regulação biopolítica pelos próprios cidadãos. Aqui a questão pedagógica é essencial como reguladora e disciplinadora, pela necessidade do rigor no trabalho artístico, apesar da sua fachada libertária. Grande parte desse trabalho é feito na educação não formal, onde um sem número de procedimentos são criados, com caráter mais ou menos tecnicista, com discursos e práticas variando entre a defesa da inclusão social e a libertação dos modos de subjetivação.

Observa-se, no entanto, que as práticas de arte-educação são altamente subjetivadoras, na construção de um sujeito empreendedor de si mesmo, que pode, com esse processo pedagógico, ser capaz de governar a sua vida a partir de um novo ponto de vista, mais apto e encontrar soluções criativas para lidar com a precariedade social. Observa-se ainda, nesses discursos e práticas, uma certa perversidade, ao se proclamar a execução desses empreendimentos com base no prazer, outra natural associação à atividade artística, tendo, no senso comum, o artista como alguém que trabalha "por amor" ao "se fazer o que gosta". No entanto, a prática artística é, também, extremamente dolorosa, o convívio da criação coletiva, no caso do teatro, é altamente conflitante e o empreendimento de uma obra artística é extremamente difícil e de pouca inserção num mercado de trabalho altamente competitivo. Onde estaria então toda liberdade prometida?

Outro aspecto dessa lógica governamentalizada² da prática artística é a necessidade que se cria de explicá-la cientificamente e empresarialmente. Antes se escreviam manifestos, cadernos de reflexão, diários de encenação. Hoje se escrevem projetos exemplarmente planificados, teoricamente embasados, com planilhas, gráficos, orçamentos, planos de metas. Esse modo de operação passa a reger a atividade artística financiada tanto pelo Estado como pelas parcerias público-privadas. E isso naturalmente implica em um diferente tipo de produtividade artística, altamente discursiva, referenciada, intelectualizada, tecnicizada, em uma produção massiva e em uma atividade do espectador também referenciado, planificado, que deve dar conta de todas as produções e tendências. Cria-se o padrão de uma arte fortemente referenciada pela questão da produtividade, da expertise, do planejamento estatístico. Que tipo de artista e de espectador de arte cria-se hoje então?

O homem empreendedor de si mesmo seria um homem que encontrou e satisfez os seus desejos. Mas o empreendimento o esgota, de tal forma que o desejo desaparece, permanecendo a cobrança do acerto. No neoliberalismo governa-se a

\footnotetext{
2 Governamentalidade é um neologismo criado por Foucault que procura relacionar os termos "governo" e "mentalidade", a fim de sintetizar a maneira de se governar do neoliberalismo. Este se detém sobre o controle medido, calculado e racionalizado das condutas humanas, individuais e em sociedade. Cria-se uma razão de Estado que se expressa não mais por meio de tradições, mas pela condução racionalizada (além de normatizada) das estruturas de poder, dos valores sociais e das necessidades dos sujeitos.
} 
partir das necessidades dos cidadãos, estimulam-se então desejos que não se realizam efetivamente, então se criam doenças e frustrações, que precisam ser curadas. $E$ temos a arte novamente, como grande possibilidade curadora das almas, dos espíritos cansados, dos corpos sem tesão. Mas por quanto tempo essa liberdade perdura? Ou não é, de fato, do caráter da liberdade o perdurar? Qual seria de fato a pergunta: seria a busca da felicidade, do bem estar social? Estamos aqui falando do que seria o fim último da vida?

Dentro da imensa complexidade da vida humana e de suas redes de relações, estar aqui não comporta ser, simplesmente, uma tentativa de se cumprir objetivos inalcançáveis, de completar um quadro pré-determinado de si, ou simplesmente encontrar maneiras de subsistência. Existe algo nesse silêncio da criação, na solidão que faz surgir o grito, que nos faz criar os sentidos dos nossos aprendizados.

Pode-se então perguntar, com relação à arte, onde está a vida, onde está o susto? Se a governamentalidade é a jurisdição de si e dos outros, pergunto-me então como, em suas relações de veridicção, a arte se coloca, ao mesmo tempo, como um falso poder libertário dos processos de subjetivação e, ao mesmo tempo, um espaço de real possibilidade de criação de contracondutas? Qual então o paradoxo do artista hoje? Qual a sua agonística?

Ao se criar uma nova norma, instrumentalizando-se os sujeitos, ou em uma técnica, ou em um modo de se fazer teatro, ou em uma possibilidade empreendedora do fazer artístico, troca-se um modo de subjetivação por outro, uma relação de verdade por outra. Não se pode realmente fugir disso, mas onde se encontram então os espaços liminares onde se escapa ao controle, dentro dos próprios processos? Onde encontramos a experiência de abandono de nós mesmos, de renovação constante, de vida nômade?

Jerzy Grotowski enfatizou muitas vezes que a sua busca, em meio ao trabalho artístico, era responder à questão: como se deveria viver? Em sua trajetória no teatro, chega a um ponto no qual interrompe a produção de espetáculos e se propõe a buscar a "arte como veículo". Pode-se compreender essa atitude como uma abertura para o campo da experiência, abandonando um legado discursivo sobre o teatro e sobre a sua relação entre atores e espectadores e propondo uma experiência por meio de técnicas de si que seriam essencialmente ético-estéticas.

Vivencia-se então, por meio da atividade artística pura e simples, a questão do espaço íntimo, do aprender a viver e morrer. O ser humano vê-se hoje, desgraçadamente confrontado com a própria falta de sentido da vida, a própria aversão ao sofrimento, o próprio despreparo para o silêncio, para o contentamento, para a simplicidade. E a conquista disso não tem nada a ver com a soberania dos discursos travestidos de democracia. Tem a ver com vivenciar-se outro tempo, com encontrar-se em outro tempo com a vida. Voltando-nos novamente para as práticas teatrais, indicamos novamente a questão com relação ao olhar: o que o teatro hoje, em meio à sua agonística entre a liberdade e o poder, se propõe a mostrar? O que se faz enxergar, vivenciar, tanto pelos seus atuantes como pelos seus espectadores?

Peter Brook nos chama a atenção para uma certa qualidade da obra artística, que nos levaria à vivência desse outro tempo, e que estaria imersa na beleza e na 
imaginação. Pergunto-me se, no esgotamento das problemáticas da arte enquanto produção, enquanto libertadora das amarras sociais seríamos capazes de nos investir de uma verdadeira radicalidade que nos suspenda no espaço vazio e nos leve à casa perdida do tempo. Qual o lugar desse silêncio? Devemos talvez voltar o nosso olhar para quando as práticas artísticas e pedagógicas se desmantelam: para quando acaba o fomento, pra quando o aluno deixa as aulas de teatro porque tem que arrumar um emprego, pra quando outra enchente vem e nada mudou na comunidade, a não ser no seu espaço íntimo, para quando se deparam com o louco compartilhando os procedimentos de ensaio de um coletivo, para quando se desiste de fazer espetáculos e se assume os produtos como processos ininterruptos.

Talvez a própria crise da forma teatral e de seus procedimentos seja o limiar, não apenas para as práticas artísticas, mas também para as práticas discursivas relacionadas à arte. Porque não se trata de julgar a arte ou os artistas, mas de colocar em questão o ethos que move as relações entre arte e sociedade, entre arte e política, como lugar de resistência. Afinal, está se resistindo a quê? Para que as coisas precisam sobreviver? Em lugar, deveria se perguntar: o que precisaria viver?

\section{A II Trupe de Choque e a Pedagogia da Desrazão}

Encontramos no trabalho da /I Trupe de Choque ${ }^{3}$, na cidade de São Paulo, uma das esteiras das lutas de resistência e contraconduta, no seu próprio processo artístico e na relação com as comunidades com as quais dialogaram em seu trabalho. Ao se encontrarem e se confrontarem com seus locais de residência, operaram a ação cultural de maneira integrada à ação artística e pedagógica.

Partindo de uma formação híbrida, entre artistas formados na Universidade de São Paulo e artistas das periferias, a II Trupe de Choque assumiu o papel de agente cultural ao empreender seus projetos de pesquisa com base na relação com a cidade, suas histórias e suas instituições. Definindo sua existência para além das normas e dos espaços dominantes, o grupo encontrou, ao longo de sua trajetória, desafios que fizeram questionar seu papel como agente ativo de interferência política, reconfigurando os seus territórios, entre um lugar de contestação e desvio e um lugar afirmativo de ação artística.

Ao residir em espaços de exclusão (a Usina de Compostagem de Lixo de São Matheus e o Hospital Psiquiátrico Pinel) e formação (escolas estaduais), a Trupe pôde consolidar sua pesquisa teórica e estética, sua vivência comunitária e a coletivização de seus processos artísticos e pedagógicos. O subsídio público ao seu trabalho possibilitou ao grupo o estabelecimento da sua situação marginal, ao protegê-lo de uma necessidade de expansão ou validação pelo mercado, o que restringiria a sua liberdade de experimentação artística.

\footnotetext{
3 A /l Trupe de Choque foi um coletivo que atuou por mais de 10 anos nas periferias na cidade de São Paulo, sob direção de Ivan Delmanto. De constituição híbrida entre atores de formação universitária, artistas da periferia e artistas que empreenderam parte da sua formação no próprio grupo, a Trupe buscava integrar arte, pedagogia filosofia e ação política no seu trabalho. Contemplada em várias edições da Lei de Fomento ao Teatro, o grupo fez residência artística em três espaços públicos localizados em regiões distintas e periféricas da cidade: a Usina de Compostagem de Lixo em São Matheus (zona leste), o Hospital Psiquiátrico Pinel (zona oeste) e as Escolas Estaduais Carlos Ayres e Esther Garcia (zona sul). O contato com os diferentes espaços, seus frequentadores, sua vocação pública e sua história foram determinantes na concepção e desenvolvimento dos projetos empreendidos pela Trupe, a partir de um diálogo político e filosófico entre sua pesquisa artística e os espaços de formação, exclusão e despossessão na própria cidade de São Paulo.
} 
Ao interferir no espaço público, a II Trupe de Choque encontrou o cerne da sua ação cultural, dialogando artística e politicamente com as instituições e as comunidades que por ali transitavam, buscando sua resistência nos próprios encontros e confrontos estéticos e culturais que o trânsito pela cidade e suas instituições públicas proporcionaram.

Eu acho que só se torna uma vivência política quando a gente consegue fazer parte dessa experiência que é da cidade inteira. Às vezes, quando eu me sinto muito frustrado, eu me seguro nisso, que a gente não está sozinho ali. Às vezes eu sinto mais a interferência da cidade na gente do que da gente na cidade. Então eu sinto que a gente está mais invadido pela cidade do que a gente a invade. Acho que não saberia medir o quanto, mas de algum jeito a gente interfere (informação verbal). ${ }^{4}$

Ao refletir sobre o seu papel como artistas, sobre sua relação com o espaço e sobre a dialética existente entre os artistas e suas obras e a sociedade, o grupo lançou-se ao encontro do que estaria situado além das suas próprias margens, equilibrando-se entre a sua sobrevivência e a resistência às forças e formas que criticavam, numa existência envolta em paradoxos e desterritorializações.

A partir da residência da // Trupe de Choque no Hospital Psiquiátrico Pinel, na periferia oeste da cidade de São Paulo, pode-se refletir sobre algumas relações possíveis nos cruzamentos entre arte e realidade, perpassados por experiências de formação e transformação dos sujeitos e dos espaços. Motivados pelas perguntas: como estabelecer a reflexão em um lugar no qual o pensamento racional é afetado pela reclusão e pela doença? Como entrar em processo artístico com pessoas abandonadas e em sofrimento psíquico? Como estabelecer a relação entre artistas, internos e espectadores? A /I Trupe desenvolveu um modo de trabalho que chamou de pedagogia da desrazão.

Ao investigar a história da loucura, Foucault observou a relação entre razão e desrazão, apontando para a ideia de que nem sempre a loucura foi um conceito oposto à razão, mas que, ao longo da história, desenvolveram-se numa relação contingente, caracterizada pela ausência e pela exclusão. A // Trupe de Choque abraçou assim a ideia de desrazão como o negativo da lógica perversa do mercado, da razão administrada e da sujeição pela indústria cultural. Desenvolveram sua ação artístico-pedagógica integrando artistas, internos e espectadores nos fundamentos da experiência criativa em teatro, baseando sua pesquisa nas contradições da formação social e nas ruínas da desigualdade metropolitana.

E no Pinel tinha mais uma dificuldade, que era lidar com pacientes psiquiátricos, pessoas que estavam dopadas, que tinham alucinações, que confundiam a realidade com delírio. E a ideia era que a gente fizesse os Núcleos com eles. Aí foi muito bonito, porque acho que eles ensinaram muito para o grupo. Foi todo um modo de trabalho mesmo, que a gente chamou de desrazão. Mas foi pra além disso. Foi pra nossa organização, pra nossa forma de pensar a arte. Mudou completamente, porque era uma realidade muito dura e, ao mesmo tempo, a gente se perguntava: o que estamos fazendo aqui? Qual a relevância de se fazer arte aqui num hospital, com os pacientes tão debilitados? Mas quando você via um paciente que tinha de-

4 Ivan Delmanto em entrevista à autora, em junho de 2016. Os depoimentos citados neste artigo e a experiência da // Trupe de Choque são encontrados em Suzana Schmidt Viganó. Por entre as trilhas chuvosas de uma travessia: teatro, ação cultural e formação artística na cidade de São Paulo. 2017. Tese (Doutorado em Artes Cênicas) - Escola de Comunicação e Artes, Universidade de São Paulo, São Paulo, 2017. 
cidido não falar mais, começando a falar durante um aquecimento, isso era muito forte e nos dava algum sentido de estar ali. Não íamos salvar o mundo, mas pelo menos íamos trocar experiências com essas pessoas. E a gente se amparou muito nisso, em trocar experiências mesmo (informação verbal). ${ }^{5}$

Ao empreender o processo artístico-pedagógico em meio ao campo do dilaceramento dos sujeitos a aventura teatral constituiu-se no abismo entre o saber e o não saber, formalizando-se em constante construção e destruição. Ao compartilhar seus modos de criação e produção com os internos e os espectadores, nos encontros abertos chamados de Detritos de Ensaio; e nas próprias práticas desenvolvidas cotidianamente no Pinel, A // Trupe foi de encontro aos "mestres ignorantes", performers da sua própria existência e experiência artística.

Sempre tive dificuldade de propor algo no convívio, pois é o lugar no qual considero mais difícil a comunicação com os pacientes. Logo quando se entra, vê-se uma escada e no fim dela um corredor onde ficam os quartos. [...] Era para que eu ficasse observando como diretora, mas acabei me comunicando através da fita adesiva e de um canetão com um paciente. Colava um pedaço de fita no meu corpo, e ele com o canetão rabiscava em cima todas as vezes que eu realizava essa ação. Então retirava a fita do meu corpo e colocava nele, na mesma parte do corpo que estava colado no meu. Fizemos isso por um longo tempo. Quando esse código se estabeleceu comecei a colar a fita por todo o espaço e ele vinha e escrevia (rabiscava) na fita. Encontramos um meio e nos comunicamos através dele, eu com a fita adesiva, ele com o canetão, coisa que nunca havia conseguido. Percebi que até aquele momento estava tentando me comunicar através da fala, da razão, mas o corpo conseguiu se comunicar sem uma só palavra. Foi assim a minha primeira conversa com um paciente do convívio. (Nascimento, 2012, p. 50)

O grupo estabeleceu experiências pedagógicas singulares com os internos. $O$ trabalho de criação artística, lúdica e performática entre atores e pacientes no Pinel dava-se na reconfiguração dos territórios internos, tanto dos pacientes e dos atores como do próprio hospital. Para Guattari, o processo de singularização e da produção de si organizam-se segundo a criação de territórios sensíveis. A produção de um novo saber e de uma nova existência deve configurar-se em um universo anterior à linguagem e à narrativa, abrindo novos sistemas de referência, como se dá, por exemplo, na criação artística. A pesquisa da // Trupe de Choque, centrada na ação discursiva das narrativas ensaísticas e dramatúrgicas é rompida no trato com os pacientes do Pinel, confrontando aqui seus próprios materiais e modos de produção.

O que deveria ser um simples jogo transformou-se na possibilidade de encontro entre os integrantes daquele núcleo. Formou-se uma grande comitiva pelo Pinel, onde o único objetivo era seguir o líder. Instaurou-se a proposta de que o líder cumprimentaria todos os que passassem por ele, além de convidá-lo para a atividade. O que não deveria extrapolar o espaço de uma residência se transformou numa imensa matilha, cada participante ao seu modo, tempo e possibilidade realizava a proposta de caminhar pelo espaço do hospital conduzido pelo líder do movimento. Da pequena roda formada em frente à residência, as diversas irmãs Grunhild e Ella caminharam pelo hospital passando por quase toda sua parte habitada. [...] Os textos e movimentos se misturaram ao ponto de não se saber ao certo mais quem liderava o coletivo. Finalizamos o exercício depois de um longo tempo de experimentação. Em determinado tempo da caminhada as atrizes pro-

5 Amanda Cavalcante em depoimento à autora, em maio de 2014. 
puseram passagens dos diálogos da peça, assim como ações que estavam pesquisando com os personagens. O que ocorreu no final foi uma grande improvisação de cena na quadra do Pinel. (Oliveira, 2012, p.20).

O trabalho artístico-pedagógico da /l Trupe de Choque veio ao encontro da emancipação por meio da apropriação do próprio processo criativo, que se deu, no entanto, ao se partilhar o sensível para fora da hierarquia do conhecimento. Os encontros com os pacientes se davam, dessa maneira, em torno de temas, personagens, ações performativas, jogos e exercícios cênicos e plásticos que se relacionavam com o universo de autores diversos como Sófocles, Shakespeare, Brecht, Eugene O'Neill, Tchekhov, Ibsen e Vianinha. A interação com os pacientes dava-se em constante descoberta, e as experiências vivenciadas nos $\mathrm{Núcleos}^{6}$ passavam a alimentar as propostas cênicas, reorganizadas posteriormente nos ensaios. A tendência da produção artística no Pinel, todavia, formalizou-se em linguagens performáticas e performativas, operando nos limites das pulsões de vida.

A experiência próxima da Trupe com a loucura, o confronto do seu trabalho racional, intelectualmente organizado, com a lógica da desrazão e a vivência da reclusão em um hospital psiquiátrico levaram o grupo a presenciar estados de existência que colocaram em xeque seus conceitos, suas obras e suas formulações sobre a sociedade. No jogo entre mestres e ignorantes proposto pela Trupe os internos foram os canais pelos quais a intensidade se revelou; encontrando a arte em outro tempo com a vida.

\section{A ideia de resistência}

Para Foucault (1985) as resistências definem-se no campo estratégico da relação com o poder: onde existe poder existe resistência. Os pontos de resistência distribuem-se de modo irregular no tempo ou no espaço, podendo provocar o levante de grupos e indivíduos, criando neles regiões irredutíveis. "Para resistir, afirma Foucault, é preciso que a resistência seja como o poder, tão inventiva, tão móvel, tão produtiva quanto ele e que, como ele, venha de baixo e se distribua estrategicamente" (Grabois, 2011, p.12). Hoje, as relações entre arte e política são acompanhadas largamente pela ideia de resistência, de oposição ao poder como conduta. Para a II Trupe de Choque, por exemplo, isto se deu pela sua ação artística em relação com a cidade de São Paulo e suas instituições públicas.

Eu penso muito nisso, sabe. Eu me pergunto se é uma ação política nossa estar aqui, se isso é resistência. Para mim é uma resistência muito grande vir pra cá, me deslocar até o Grajaú. Eu trabalho toda manhã no lado oposto da cidade, na zona norte. Então, vir pra zona sul, lidar com os pensadores que a gente lida, com toda a dificuldade que eu tenho de compreensão, de apreensão dos textos e mesmo assim continuar insistindo, eu acho que é uma forma de resistir. Para não sucumbir e deixar a mente se perder completamente nesse mundo do consumo de tudo, do consumo do outro, dos objetos, de consumir a vida e não viver de uma

6 Os Núcleos Peripatéticos de Pesquisa eram o espaço de experimentação pedagógica da /I Trupe de Choque. Organizados a partir da ideia de oficinas de linguagens diversas, os Núcleos acabaram constituindo-se em experiências singulares no campo artístico-pedagógico, processualizadas a partir dos encontros e confrontos com os espaços de residência artística. O trabalho dos Núcleos Peripatéticos de Pesquisa é mais detalhado na tese de doutoramento Suzana Schmidt Viganó, op.cit., 2017. 
forma mais coerente, de uma forma mais intensa mesmo. Então eu vejo o trabalho do grupo como um trabalho de resistência pelo que eu já falei, de pessoas de todos os níveis sociais se reunirem, estarem juntas, lidarem com as contradições do que isso implica, criarem juntas, estarem aqui e não em um lugar mais fácil de se locomover. Eu acho que se a gente não estivesse aqui, quem estaria? Quem teria a ideia de ir para duas escolas no extremo sul? Acho que quase ninguém se aventuraria, porque é difícil, não é confortável. É muito desconfortável, em todos os sentidos da palavra. Mas ao mesmo tempo, acho que faz a gente crescer. Eu acho que eu entendo um pouco isso, que resistir é estar aqui (informação verbal). ${ }^{7}$

Foucault (1995) observou que, na contemporaneidade, em meio ao modo governamentalizado de se operar o poder, as lutas de resistência fizeram surgir movimentos específicos, tendo como objetivo a busca de uma nova conduta, de se definir uma nova maneira de se conduzir (em oposição à maneira do controle racionalizado e normativo e homogeneizante da governamentalidade). Entre as formas de contraconduta atuais, Foucault observa: as que fazem frente às formas de dominação; as que contestam maneiras de exploração; e as lutas contra a sujeição. Essas lutas questionam o estatuto do indivíduo e os privilégios do saber e buscam maneiras de se autogovernar, de se libertar de uma forma de dominação assujeitante.

Compreendendo a ideia de resistência não como oposição ou permanência, mas como o movimento que resulta em uma clivagem possível na relação entre saber, poder e subjetividade, permitimos que se operem novas configurações dos terrenos percorridos historicamente, levantando novamente a questão: quem somos nós? Tal movimento, no entanto, envolve o risco, pois confrontam as linhas que cruzam de um ponto ao outro: enunciados, identidades, ideários, sobrevivências, ausências, paixões, imprevisibilidades, catástrofes.

Há muito que pensadores como Espinoza e Nietzsche mostraram que os modos de existência deviam ser pensados segundo critérios imanentes, segundo aquilo que detêm em possibilidade, em liberdade, em criatividade, sem nenhum apelo a valores transcendentais. Foucault alude a critérios "estéticos", entendidos como critérios de vida que, de cada vez, substituem pretensões de um juízo transcendente por uma avaliação imanente. (Deleuze,1996, s/p)

Nesse sentido, a experiência artística, ao operar tais critérios, permite a ultrapassagem das linhas de crise, operando a reconfiguração dos territórios. Para a /I Trupe de Choque, a residência do grupo no hospital psiquiátrico detonou não apenas a revisão dos seus modos de trabalho, mas também a sua relação com a obra artística. Para os internos, por outro lado, gerou formas de contraconduta em seus modos cotidianos de ser e na relação com a doença e a instituição.

A experiência dos Núcleos com os internos, a prática de ensaios nas dependências do hospital e o convívio com o seu cotidiano e suas mazelas levaram o grupo a repensar também a experiência da fruição da obra artística. Ao abandonar o espetáculo acabado e propor a vivência da construção da obra com seu público, a Trupe levou ao limite a relação entre teatro e pedagogia. O espectador passava a ser, efetivamente, ator, diretor, iluminador, apreciador, mestre e aprendiz da obra teatral. Esta se renovava a cada experiência, e tanto atores como espectadores colocavam-se à

7 Amanda Oliveira em depoimento à autora, em maio de 2014 
disposição de uma construção coletiva. Vivenciar parte do processo ao lado dos pacientes do hospital colocava também uma experiência limite, tanto na aceitação do outro como na quebra de qualquer julgamento sobre erros ou acertos na composição do trabalho.

Jacques Rancière (1988), ao estudar as lutas de resistência dos operários, observou que a emancipação não dizia respeito a adquirir conhecimento sobre a sua opressão; mas tratava-se de reconfigurar o tempo e o espaço de maneira que suas noites não fossem simplesmente reparadoras de forças, mas também experiência estética e criativa. Coloca-se então a questão: o que seriam esses jogos reversíveis entre verdade, subjetividade, normas e instituições com relação à arte? Qual o nosso verdadeiro alcance sobre isso? Onde estaria então o vazio que nos conecta a uma outra possibilidade de vida? Seria na prática artística em si, na sala de ensaio? Seria na apresentação pública do espetáculo, na relação da obra com a intimidade do espectador? E o que se produz a partir desses hiatos?

Pra mim resistir é isso. É conseguir sobreviver num lugar que tem tudo pra acabar com você. E aí eu vejo o jovem, a molecada, quando vão pra cima... Resistir é ter esse espírito demolidor do jovem, é esse processo de antropofagia, de construção e desconstrução o tempo todo. Mas é também aquele cara que mora nas imediações do Esther Garcia ${ }^{8}$ que talvez não tenha esse espírito de destruição, de desconstrução, mas que consegue sobreviver naquele lugar, onde ele teria tudo pra morrer com 20, 30 anos ou até menos. Uma experiência muito interessante na Trupe foi a visita ao cemitério do Parque Santo Antônio, em 2008 ou 2009. Lá, a pessoa é enterrada e eles plantam uma cruz com dados mínimos: o nome da pessoa, data de nascimento e quando morreu. Então lendo essas informações em cada cruz, eu creio que setenta por cento das pessoas que foram enterradas ali, dos meninos em especial, tinham menos do que 17 anos. Então viver já é uma resistência. Mas se tiver esse espírito demolidor, aí é uma resistência ativa. Acho que resistir é ter esse espírito demolidor, pra ser ativo nesse processo. (informação verbal). ${ }^{9}$

Mas por onde se escapa? Talvez pela própria vida, pela vida atenta, dolorida, impossibilitada, esgotada. E, dessa maneira, ao invés de colocarmos propostas edificantes possamos nos voltar à simples ideia de ultrapassagem, de atravessar as fronteiras, de desestabilizar e estabilizar constantemente, de criar atos estéticos que possibilitem novas formas de subjetivação a partir do governo de si. A luta contra a sujeição, seja do Estado, da mídia ou da indústria cultural, contra a submissão da subjetividade ganha neste momento atual cada vez mais importância. Enquanto houver poder (e não tirania ou obediência irrestrita) haverá espaço para as formas de resistência: contracondutas, sublevações, lutas sociais e políticas.

Os artistas que, como a II Trupe de Choque, se colocam como seres fronteiriços, atuando entre as margens de um e de outro grupo cultural, de um e de outro espaço urbano, de uma e de outra realidade social, têm à frente de si o desafio de tornarem-se tradutores dos encontros conflituosos entre forças de diversas naturezas e propositores de experiências que se constituam no campo aberto dos focos de resistência. E é nesse espaço fraturado que se corre ao encontro de um corpo voltado à

8 Escola Estadual Esther Garcia, no Grajaú, extremo sul da cidade de São Paulo.

9 José Maurício Lima, em entrevista à autora, setembro de 2014. 
criação e ao enfrentamento das idiossincrasias e conflitos da sociedade contemporânea. A ultrapassagem das linhas de crise e das formas de opressão, no âmbito da ação artística, nasce assim do encontro e do confronto que se dá entre os artistas, as cidades e os grupos sociais, exigindo de seus atores a revisão de seus papéis, práticas e relações, possibilitando a recriação da existência como singularidade e respiro.

\section{Referências}

CAVALCANTE, Amanda. Entrevista concedida a Suzana Schmidt Viganó. São Paulo, 15 de maio de 2016.

DELEUZE, Gilles. O que é um dispositivo. In: O Mistério de Ariana. Lisboa: Vega Passagens, 1996. Disponível em: http://www.uc.pt/iii/ceis20/conceitos_dispositivos/ programa/deleuze_dispositivo, Acesso em: 18 jul. 2019.

DELMANTO, Ivan. Entrevista concedida a Suzana Schmidt Viganó. São Paulo, 06 de junho de 2016.

FOUCAULT, Michel. Aula de 8 de fevereiro de 1978. IN: Segurança, Território e População. São Paulo: Martins Fontes, p.155-180, 2008.

FOUCAULT, Michel. História da Sexualidade, vol.1 - a vontade de saber. Rio de Janeiro, Graal, 1985.

FOUCAULT, Michel. O sujeito e o Poder. In: DREYFUS, H.; RABINOW, P. Michel Foucault, uma trajetória filosófica. Rio de Janeiro: Forense Universitária, P.231-249, 1995.

GARBOIS, Pedro Forniciari. Resistência e revolução no pensamento de Michel Foucault: contracondutas, sublevações e lutas. Cadernos de Ética e Filosofia Política 19, pp.07-27, 2/2011,

LIMA, José Maurício. Entrevista concedida a Suzana Schmidt Viganó. São Paulo, 22 de setembro de 2014.

NASCIMENTO, Leila. "Esperando Godot com os moradores do Pinel". Em Negativo, ano II, número 3. São Paulo, junho/2012, p.50.

OLIVEIRA, Sansorai. “O começo, o meio e o fim”. Em Negativo, ano II, número IV, São Paulo, novembro/2012, pp.17-21.

RANCIÈRE, Jacques. A Noite dos Proletários, São Paulo: Companhia das Letras, 1988.

SENELLART, Michel. A Crítica da razão governamental em Michel Foucault. Tempo Social, Rev. Soc. USP, São Paulo 7 (1-2) 1 a 14 outubro de 1995. 
Suzana Schmidt Viganó. Por entre as trilhas chuvosas de uma travessia: teatro, ação cultural e formação artística na cidade de São Paulo. 2017. Tese (Doutorado em Artes Cênicas) - Escola de Comunicação e Artes, Universidade de São Paulo, São Paulo, 2017.

Recebido em: 30/07/2019

Aprovado em: 17/10/2019 